\title{
Codex Alimentarius: a segurança alimentar sob a ótica da qualidade
}

\author{
Antonio César Ortega ${ }^{1}$ e Michelle da Silva Borges ${ }^{2}$
}

As crises e escândalos alimentares, ocorridas principalmente a partir de meados de 1990, tiveram repercussões negativas no mercado mundial de alimentos, perturbando o fluxo de comércio e a confiança dos consumidores. Para que este mercado não entrasse em colapso foram acionados mecanismos que restabelecessem a dinâmica do ambiente institucional do mercado de alimentos, o qual engloba entre outros, o setor público, organismos não governamentais e consumidores. Assim, garantir a inocuidade dos alimentos passou a ser uma meta conjunta de todos os agentes econômicos envolvidos neste mercado. Entre esses mecanismos, destaca-se o Codex Alimentarius. O objetivo desse trabalho é analisar o papel e o funcionamento do Codex no mercado mundial de alimentos. Conclui-se que, ao fazer parte dos Acordos da Organização Mundial de Comércio (OMC), o Codex passou a integrar a agenda política internacional, fazendo parte de um poderoso arcabouço legal para regulamentação do mercado de alimentos. Os países desenvolvidos são os maiores beneficiários desses acordos, uma vez que possuem maior grau de organização, tanto no campo científico-tecnológico, quanto no jurídico, para seguir essas normas e cobrar suas aplicações. Entretanto, os países em desenvolvimento precisam definir políticas públicas e de aperfeiçoamento de seus sistemas de controle, prevenção e inspeção, cuja capacidade e custos vêm apresentando dificuldades.

Palavras-chave: segurança alimentar, inocuidade, Codex Alimentarius.

\section{Codex Alimentarius: the perspective of quality}

The crisis and food scandals that occurred from mid-1990, had serious and negative repercussions in the global food market, disrupting the flow of trade and consumer confidence. For this market has not collapsed, from crisis to crisis, were created and driven mechanisms that reestablished the dynamics of the institutional environment of the food market, which includes among others, the public sector, nongovernmental organizations and consumers. Thus, to ensure food safety has become a joint economic agent involved in this market. Among these mechanisms, there is an intergovernmental Program, the Codex Alimentarius. The aim of this study is to analyze the role and functioning of Codex in the global food market. It is concluded that the part of the World Trade Organization (WTO) Agreements, the Codex has joined the international political agenda, as part of a powerful legal framework to regulate the food market. Developed countries are major beneficiaries of these agreements, since they have a higher degree of organization, both in science and technology, as in law, to follow these rules and collect applications. However, developing countries need to define public policy and improve its systems of control, prevention and inspection, whose capacity and costs have presented difficulties.

Key-words: food security, food safety, Codex Alimentarius.

\footnotetext{
${ }^{1}$ Professor Associado IV do Programa de Pós-Graduação em Economia do Instituto de Economia, Universidade Federal de Uberlândia (UFU). Correspondência: Instituto de Economia, UFU. Av. João Naves de Ávila, 2121 - Campus Santa Mônica. Bloco 1J. CEP: 38408-902. E-mail: acortega@ufu.br.

${ }^{2}$ Doutoranda do Instituto de Economia, UFU. Programa de Pós-Graduação em Economia, UFU.
} 


\section{INTRODUÇÃO}

A segurança alimentar é um tema estratégico para os países, incorporada por ideários das políticas agrícolas, pelo conjunto de políticas socioeconômicas voltadas para o combate à pobreza, pela pesquisa e desenvolvimento agroindustrial, pela saúde pública, pelo controle e vigilância sanitária e nos debates em torno do direito ao consumidor ${ }^{[1]}$.

Segurança Alimentar é um conceito construído ao longo das últimas décadas do século XX à medida que o confronto do problema da fome demonstrava a necessidade de ações mais amplas para o enfrentamento desse flagelo da humanidade.

A expressão "segurança alimentar" ganhou proeminência no Pós-Segunda Guerra, particularmente na Europa, ligada à ideia de que, para fazer face ao desabastecimento alimentar que se verificava naquele momento no continente, era preciso aumentar a oferta de alimentos. Essa ampliação da oferta, além de atender às necessidades de sua população, contribuiria para com a balança comercial dos países europeus. Difundiu-se, assim, a chamada Revolução Verde e criou-se um forte aparato de apoio aos agricultores (crédito e assistência técnica) para elevação da produção. A questão da segurança alimentar, naquele momento, podemos concluir, estava ligada exclusivamente à capacidade de produção de alimentos dos diversos países.

A forte crise da oferta de alimentos, no início da década dos anos de 1970, com sucessivas quebras de safras agropecuárias devido a problemas climáticos, particularmente na África, fez disparar novamente o sinal de alerta e motivou a realização da I Conferência Mundial de Alimentação, promovida pela Organização das Nações Unidas para Alimentação e Agricultura (FAO), em 1974.

Como resultado dos debates e acordos, o objetivo estabelecido era de que:

[...] ao término de uma década, não haja nenhuma criança que tenha que se conformar sem ter satisfeito sua fome, nenhuma família que tema pelo pão do dia seguinte, $\mathrm{e}$ que nem o futuro nem a capacidade de nenhum ser humano seja prejudicado pela má nutrição (p. 32) [2].
Foram estabelecidas as seguintes prioridades: intensificar a produção de alimentos; ampliar a utilização de insumos modernos; ampliar a pesquisa agronômica; melhorar as atividades de extensão e capacitar os agricultores; políticas e programas para melhorar a nutrição; carta mundial dos solos e avaliação do potencial de produção das terras; ordenamento científico das águas, irrigação, armazenamento e luta contra as inundações; ampliação do papel da mulher; equilíbrio entre a população e a oferta de alimentos; fomento à indústria de sementes; redução dos gastos militares para aumentar a produção de alimentos; ajuda alimentar às vítimas das guerras coloniais na África; criação do Sistema Mundial de Informação e Alerta sobre a Alimentação e a Agricultura; melhoria das condições de acesso ao comércio internacional de alimentos ${ }^{[2]}$.

Todavia, nota-se que os resultados da Conferência ainda refletiam o entendimento de que a segurança alimentar estava estritamente ligada à produção agrícola. Assim, os compromissos e as resoluções acordados na Conferência, proclamados na "Declaração Universal sobre a Erradicação da Fome e Má Nutrição" voltam-se fundamentalmente para o aumento da oferta alimentar e para as atividades emergenciais.

Entretanto, a persistência da fome levou a discussão sobre a segurança alimentar a novos rumos, pois, ainda que fossem mantidos enormes estoques de alimentos, particularmente nos países desenvolvidos, o problema estava longe de ser resolvido. Desloca-se, portanto, o foco do debate para a garantia do acesso da população aos alimentos. Assim, o tema da Segurança Alimentar deixou de ser discutido pela ótica estritamente produtiva e agregou a questão da distribuição.

É nesse contexto que o conceito de segurança alimentar é ampliado e, na XII Conferência Mundial, em 1989, a FAO propôs:

O objetivo final da Segurança Alimentar Mundial é assegurar que todas as pessoas tenham, em todo momento, acesso físico e econômico aos alimentos básicos de que necessitam (...) a segurança alimentar deve ter três propósitos específicos: assegurar a produção alimentar adequada; conseguir a máxima estabilidade no fluxo de tais alimentos e garantir o acesso aos alimentos 
disponíveis por parte dos que os necessitam (p. 55) [3].

Em 1996, foi realizada nova Conferência Mundial da Alimentação, reafirmando o direito de todos ao acesso a alimentos seguros e nutritivos. Chefes de Estado e demais autoridades governamentais presentes à conferência comprometeram-se a envidar esforços permanentes para erradicar a fome em todos os países. O objetivo imediato era reduzir pela metade o número de pessoas subalimentadas e, até no mais tardar, em 2015, erradicar a fome.

Desse debate originaram-se a Declaração de Roma sobre a Segurança Alimentar Mundial e o Plano de ação da Cúpula Mundial da Alimentação, que estabeleceram as bases para diversas trajetórias, de maneira a atingir um objetivo comum: segurança alimentar nos âmbitos individual, familiar, regional, nacional e mundial. De acordo com o documento:

Existe segurança alimentar quando as pessoas têm, a todo o momento, acesso físico e econômico a alimentos seguros, nutritivos e suficientes para satisfazer as suas necessidades dietéticas e preferências alimentares, a fim de levarem uma vida ativa e sã (p. 40, grifo nosso) [4].

A partir desta declaração predominou o entendimento que as políticas públicas para segurança alimentar deveriam ser dirigidas a "erradicar a pobreza e a desigualdade, melhorar o acesso físico e econômico de todos e, a todo o momento, a alimentos suficientes, nutricionalmente adequados e seguros, assim como à sua utilização eficiente" (p. 3) [4].

Portanto, a segurança alimentar não estava relacionada somente a aspectos de disponibilidade, acesso e estabilidade (elementos ligados à expressão inglesa de food security), mas, também a questões de segurança (alimento não contaminado biológica ou quimicamente) e qualidade (nutricional, biológica, sanitária e tecnológica).

As crises e escândalos alimentares, ocorridas principalmente a partir de meados de 1990, tiveram repercussões graves e negativas no mercado internacional de alimentos, perturbando o fluxo de comércio alimentar e a confiança dos consumidores. Para que este mercado não entrasse em colapso, de crise em crise, foram criados e acionados mecanismos que restabelecessem a dinâmica do ambiente institucional do mercado de alimentos, o qual engloba entre outros, o setor público, organismos não governamentais e consumidores. Assim, garantir a inocuidade dos alimentos passou a ser uma meta conjunta de todos os agentes econômicos envolvidos neste mercado.

Entre esses mecanismos, destaca-se um Programa intergovernamental, o Codex Alimentarius, que se tornou, pelo seu caráter abrangente e de fundamentação científica, uma referência (em termos de normas, regras e diretrizes) para os consumidores, produtores, processadores, agências nacionais de controle, entre outros.

Tendo em vista esta discussão, o objetivo desse trabalho é analisar o papel e o funcionamento do Codex Alimentarius no comércio mundial de alimentos. Principalmente a partir de 1995, quando ele passa a ser citado, por meio do Acordo sobre Medidas Sanitárias e Fitossanitárias (SPS) da Organização Mundial de Comércio (OMC), como ponto de referência na elaboração de normas alimentares internacionais. Para tanto, o trabalho está estruturado em quatro seções, para além dessa introdução. Na seção um a segurança alimentar é tratada pela ótica da qualidade, destacando a relevância da inocuidade dos alimentos; na seção dois trata-se do Codex Alimentarius como ponto de referência para os membros da OMC quanto à implementação de medidas de segurança alimentar (food safety); na seção três é explanado como essas normas podem ser aplicadas pelos países, e finalmente, as considerações finais.

\section{SEGURANÇA ALIMENTAR SOB O ENFOQUE DA QUALIDADE}

Sob a ótica da qualidade ${ }^{3}$, a segurança alimentar significa garantir ao consumidor a aquisição de alimentos com atributos nutricionais e sanitários

\footnotetext{
${ }^{3}$ Segundo a Organização Mundial da Saúde (OMS), os termos inocuidade e qualidade dos alimentos podem expressar alguns equívocos. Quando se fala sobre inocuidade dos alimentos se faz referência a todos os riscos, sejam crônicos ou agudos, que podem fazer com que os alimentos sejam nocivos para a saúde do consumidor. Trata-se de um objeto que não é negociável. $\mathrm{O}$ conceito de qualidade abarca todos os demais atributos que influencia o valor do produto para o consumidor. Engloba tanto, atributos negativos, como estado de decomposição, contaminação, descoloração e odores desagradáveis; como atributos positivos, como origem, cor, aroma, textura, entre outros.
} 
adequados às suas necessidades. Nessa direção, a expressão implica alimentos de boa qualidade, livres de contaminação de natureza química, biológica ou física, ou de qualquer outra substância que possa acarretar problemas à saúde do consumidor (p. 38) [1].

Essa interface da segurança alimentar ganha espaço devido às mudanças ocorridas na produção, hábitos de consumo e, principalmente, nas relações comerciais entre países. Com referência à origem dessas mudanças, Nojosa et al. ${ }^{[5]}$ nos esclarecem que:

A aceleração do processo de globalização que ocorreu nas últimas décadas do século $\mathrm{XX}$ teve impacto direto nos hábitos de consumo das populações e nas trocas comerciais da maioria dos países. Mudanças drásticas no arcabouço legal internacional surgiram entre 1947 e 1995, e continuam ocorrendo em função da dinâmica do comércio, das novas tecnologias e, principalmente, das novas necessidades da sociedade globalizada (p. 45).

Uma das mudanças mais relevantes no circuito internacional do comércio foi a criação da OMC, em 1995, resultado de um intenso e acalorado debate entre os países na Rodada do Uruguai. Essa rodada representou um marco na história das negociações comerciais multilaterais, com a introdução de novos temas na agenda e com destaque para as barreiras não tarifárias.

Como resultado das negociações da Rodada Uruguai, criou-se em janeiro de 1995 a Organização Mundial de Comércio (OMC) para suceder o Acordo Geral sobre Tarifas e Comércio (GATT) de 1947, como o órgão encarregado de criar uma ordem internacional liberal no comércio segundo regras multilaterais. A Rodada Uruguai, além da liberalização da agricultura, incorporada no Acordo da Agricultura, consolidou a maior liberalização tarifária de uma única rodada de negociações multilaterais desde os primórdios do GATT, a inclusão dos têxteis, dos serviços e de uma profusão de "novos temas" (como propriedade intelectual e investimentos) nas disciplinas multilaterais. Houve um reforço das regras do GATT em questões como subsídios, barreiras técnicas, salvaguardas, regras de origem, licenças de importação, antidumping, medidas sanitárias e fitossanitárias, valoração aduaneira, entre outros (p. 226, grifo nosso) [6].
Apesar desses princípios de regulamentação do comércio entre os países, cujo intuito é impedir restrições ao comércio internacional, as barreiras comerciais permanecem presentes. Azevedo [7] ressalta que o benefício conquistado no comércio internacional com a redução de entraves, tarifas, subsídios, questões aduaneiras, entre outros, contrapõe-se ao surgimento de outras barreiras, mais sutis, de difícil identificação, mas com a mesma função: proteger mercados. Essas barreiras são chamadas não tarifárias.

Segundo Almeida [8], três fatores têm contribuído para o aumento das barreiras não tarifárias: a diminuição da incidência de outros obstáculos ao comércio, como resultado dos acordos da Rodada do Uruguai; a fragilidade competitiva de alguns países e a crescente interdependência dos mercados.

Thorstensen [9] afirma que é rotina dos governos a adoção de regras sobre regulamentos e normas técnicas aplicadas sobre bens produzidos internamente e sobre importados, com objetivo de garantir padrões de qualidade, de segurança, de proteção à saúde e ao meio ambiente. No entanto, essas regras podem se transformar em práticas abusivas ao comércio internacional, tendo em vista a redução de tarifas e as pressões políticas para proteção de setores menos competitivos. Corroborando essa análise, Presser \& Almeida ${ }^{[6]}$ destacam que:

O processo de normalização internacional tem enorme potencial para promover maior eficiência e crescimento econômico na globalização. Entretanto, as normas e regulamentos técnicos que restringem a entrada de produtos importados que não satisfaçam determinados requisitos em matéria de saúde, segurança, qualidade, compatibilidade ou proteção ao meio ambiente podem se transformar em barreiras técnicas ${ }^{4}$ ao comércio internacional (p. 226).

\footnotetext{
${ }^{4}$ Segundo o Instituto Nacional de Metrologia, Qualidade e Tecnologia (INMETRO), Barreiras técnicas, considerando o estipulado pela OMC, são barreiras comerciais derivadas da utilização de normas ou regulamentos técnicos não transparentes ou não embasados em normas internacionalmente aceitas ou, ainda, decorrentes da adoção de procedimentos de avaliação da conformidade não transparentes e/ou demasiadamente dispendiosos, bem como de inspeções excessivamente rigorosas. Fonte: http://www.inmetro.gov.br/barreirastecnicas/barreirastecnicas.asp.
} 
Para evitar essas barreiras ao comércio, a OMC cita o Codex como ponto de referência que os países membros devem levar em consideração quanto à implementação de medidas sanitárias para seus alimentos. Pois, entre outros objetivos, o Codex propõe orientar e promover a elaboração e a definição de requisitos para auxiliar na harmonização de normas alimentares e com isso facilitar o comércio internacional. De acordo com Veggeland \& Borgen (p. 676) [10], "O estabelecimento dos acordos da OMC fez com que o Codex fosse ligado a um poderoso instrumento legal para regulamentar o comércio mundial de alimentos". Portanto, esse Programa é indispensável em qualquer discussão de normas alimentares internacionais.

\section{CODEX ALIMENTARIUS}

O Codex Alimentarius é um Programa conjunto entre a Organização das Nações Unidas para Alimentação e Agricultura (FAO) e da Organização Mundial da Saúde (OMS), criado em 1963, para elaborar e coordenar normas alimentares no plano internacional. As propostas centrais do Codex estão citadas no artigo primeiro de seu Estatuto: proteger a saúde dos consumidores e assegurar práticas equitativas no comércio internacional de alimentos. Este Programa é um fórum intergovernamental que desenvolve normas internacionais para alimentos baseado em princípios científicos. Atualmente ele conta com mais de 200 normas em relação a alimentos elaborados, semielaborados ou crus; mais de 40 códigos de práticas de higiene; tem avaliado mais de 1.000 aditivos alimentares e mais de 54 medicamentos veterinários; tem estabelecido mais de 3.000 níveis máximos para resíduos de pesticidas e tem especificado mais de 30 diretrizes para contaminantes. Ao desenvolver essas normas, o Programa estabelece uma coordenação com todas as organizações internacionais, governamentais e não governamentais, que atuam na área de alimentos, buscando apoiar-se nos centros de excelências que atuam em segmentos específicos, incluindo-os nos trabalhos dos comitês pertinentes. Atualmente, o Codex conta com 185 países (184 Estados membros e União Europeia). Estes participantes comprometem-se a criar comissões nacionais para atuarem de acordo com as deliberações realizadas em âmbito internacional [11].

Em 1995, o Codex passa a ser referido principalmente no acordo SPS da OMC e ganha proeminência na agenda da política internacional. Isso significava que, nas divergências insolúveis que pudessem surgir na $\mathrm{OMC}$, referente à questão sanitária e fitossanitária quem irá resolver a problemática será a base de normas do Codex.

\section{A comissão do Codex Alimentarius e seu funcionamento}

O Codex Alimentarius possui uma estrutura de direção composta de dois órgãos:

A Comissão do Codex Alimentarius, órgão máximo do Programa, que se compõe de todos os países membros e é a instância que aprova as normas Codex. Sua direção é composta de um Presidente e três Vice-Presidentes;

Um Comitê Executivo ao qual compete implementar as decisões da Comissão e atuar em seu nome nos períodos entre suas reuniões.

É constituído por 21 Comitês, sendo dez sobre temas gerais, cinco sobre produtos e seis Comitês regionais de coordenação. Ainda faz parte dessa estrutura grupos intergovernamentais especiais.

As funções desses Comitês são (p. 208) [11]:

- Comitês do Codex sobre Assuntos Gerais: esses comitês elaboram normas, diretrizes e códigos de práticas aplicáveis a todos os alimentos;

- Comitês do Codex sobre Produtos: esses comitês elaboram normas específicas para produtos;

- Comitês Coordenadores Regionais: esses comitês coordenam a participação dos países de uma região ou grupos de países nos trabalhos do Codex e identificam a necessidade desses países em termos de normas para alimentos.

A finalidade dessas comissões é a preparação de normas alimentares e sua publicação no Codex Alimentarius. Em resumo, a elaboração das normas passa pelos seguintes trâmites:

a) A apresentação de uma proposta relativa a uma norma pode ser elaborada por um governo nacional ou um comitê auxiliar da comissão; 
b) A decisão por parte da Comissão do executivo de que se elabore uma norma de acordo com a proposta;

c) A secretaria da comissão se encarrega de preparar um anteprojeto de norma e de distribuí-lo aos governos dos Estados Membros para que formulem observações;

d) As observações são examinadas pelo órgão auxiliar a que se tenha confiado a tarefa de elaborar o anteprojeto de norma, e que pode apresentar o texto à Comissão como projeto de norma. O projeto também pode ser enviado aos outros comitês do Codex,

e) Esse processo de elaboração das normas é extenso. Uma vez adotada pela Comissão, a norma do Codex se incorpora ao Codex Alimentarius.

Os elaboradores do Programa internacional que assentaram as bases e determinaram a orientação das atividades do Programa conjunto FAO/OMS sobre normas alimentares e de sua comissão estão preocupados, antes de tudo, em proteger a saúde dos consumidores e assegurar práticas equitativas no mercado internacional de alimentos. $\mathrm{Na}$ opinião deles, se todos os países harmonizassem suas leis alimentares e adotassem normas convencionadas internacionalmente, essas questões se resolveriam naturalmente. Isso acarretaria uma diminuição dos obstáculos ao comércio e maior liberdade de transação dos produtos entre os países, graças à homogeneização das normas; ademais redundaria em benefícios para os agricultores e suas famílias e contribuiria também para reduzir a fome e a pobreza ${ }^{[12] .}$

\section{Instrumentos do Codex Alimentarius: normas, códigos de práticas e diretrizes}

O Codex contém disposições relativas à higiene, rotulagem, resíduos de pesticidas e medicamentos veterinários, sistemas de controle e certificação de importações e exportações, métodos de análise e amostragem, aditivos, contaminantes, embalagem e apresentação. As normas para produtos tendem a ajustar-se a uma estrutura fixa estabelecida no Manual de Procedimento da Comissão do Codex. Essa estrutura inclui as seguintes categorias de informações:
- O âmbito de aplicação: inclui o nome do alimento ao qual se aplica a norma e, na maior parte dos casos, a finalidade com que se utilizará o produto;

- A descrição: inclui uma definição do(s) produto(s) contemplado, assim como uma indicação, quando seja oportuno, das matérias-primas de que procedem;

- Os fatores essenciais de composição: incluem informação sobre a composição e as características de identidade do produto;

- Os aditivos alimentares: recolhem os nomes dos aditivos e a quantidade máxima que se permite adicionar ao alimento. Os aditivos alimentares devem estar autorizados pela FAO e pela OMS, por seu caráter inócuo, e a utilização dos aditivos alimentares deve respeitar a Norma Geral do Codex para os Aditivos Alimentares;

- Os poluentes: contêm os limites de presença de poluentes autorizados no produto ou produtos regulados pela norma. Esses limites se baseiam no assessoramento científico da FAO e da OMS e devem ajustar-se à Norma Geral do Codex para os poluentes e toxinas presentes nos alimentos. Quando procede, inclui-se assim mesmo uma referência aos limites máximos do Codex para os resíduos de pesticidas e para os resíduos de medicamentos veterinários nos alimentos;

- A higiene inclui referências aos Códigos de Práticas de higiene do Codex pertinentes para o produto de que se trata. Em quase todos os casos, exige-se que o produto esteja isento de microorganismos patogênicos, de quaisquer toxinas ou de outras substâncias venenosas ou nocivas em quantidades que representem um perigo para a saúde;

- O rótulo inclui disposições sobre o nome dos alimentos e todos os requisitos especiais para garantir que não se engane ou se induza erro ao consumidor acerca da natureza do alimento. Especificam-se também os ingredientes do produto e data de validade;

- Os métodos de análises e amostragem incluem uma lista de métodos de prova necessários para garantir que o produto cumpra os requisitos da norma (p. 211) [13]. 
Os códigos de práticas do Codex - incluindo os de higiene - definem as práticas de produção, elaboração, manufatura, transporte e armazenamento de alimentos ou grupos de alimentos determinados, para garantir a inocuidade e a aptidão dos alimentos para o consumo. No que se refere à higiene dos alimentos, o texto fundamental são os Princípios Gerais do Codex de Higiene dos alimentos, que introduz a utilização de Análises de Perigos e de Pontos Críticos de Controle (HACCP $)^{5}$ para o sistema de gestão da inocuidade dos alimentos. Um código de práticas para a regulação do uso de medicamentos veterinários proporciona orientação geral neste âmbito.

As diretrizes do Codex dividem-se em duas categorias:

- Os princípios que estabelecem políticas em determinados âmbitos fundamentais;

- As diretrizes para a interpretação de ditos princípios ou das disposições das normas gerais do Codex.

Existem princípios do Codex independentes sobre a adição de nutriente essencial aos alimentos; a inspeção e certificação de importações e exportações de alimentos; o estabelecimento e aplicação de critérios microbiológicos para os alimentos; a realização de avaliação de riscos microbiológicos; as análises de riscos para alimentos obtidos por meios biotecnológicos modernos.

Entre as diretrizes do Codex de caráter interpretativo, cabe destacar as relativas aos rótulos dos alimentos, em particular a regulamentação das declarações de propriedades que figuram nas etiquetas. Nesse grupo se incluem as diretrizes para as declarações de propriedades nutricionais e saudáveis, as condições de produção, comercialização e rótulo de alimentos orgânicos. Existem várias diretrizes que interpretam as disposições dos Princípios do Codex para a inspeção e certificação de importação e exportação de alimentos, assim como diretrizes sobre a realização de avaliações da inocuidade dos alimentos obtidos a partir de plantas e micro-organismos cujo DNA tenha sido modificado.
Ocorre, entretanto, como destaca Martinelli [13], que as Normas Codex são voluntárias, ou seja, a adesão ao Programa não significa a obrigatoriedade de sua aceitação. Para cada norma aprovada, o país é consultado sobre a sua aceitação ou não, conforme o Procedimento de Aceitação de Normas do Codex. Com a criação da OMC, em 1995, na prática, essas normas têm assumido caráter obrigatório, pois as Normas Codex foram estabelecidas como referência no âmbito do Acordo sobre Aplicação de Medidas Sanitárias e Fitossanitárias (SPS) ${ }^{6}$ da OMC. Ou seja, as Normas Codex atendem aos princípios fundamentais do Acordo: não discriminação, transparência e tratamento especial e diferenciado para países em desenvolvimento.

\section{APLICAÇÃO DAS NORMAS NO COMÉRICO MUNDIAL DE ALIMENTOS}

É importante destacar que o Acordo sobre a Aplicação de Medidas Sanitárias e Fitossanitárias (SPS) da OMC impõe a cada um dos países membros determinadas obrigações em matéria de transparência. A transparência é um dos princípios fundamentais do Acordo, ela exprime um maior grau de claridade, previsibilidade e informação sobre as políticas, normas e regulamentos sobre os alimentos. Para colocar em prática este princípio os países membros utilizam notificações.

A OMC possui um sistema de dados das notificações, o que possibilita consultas a nível internacional, e permite aos países membros formularem observações sobre as medidas e normas apresentadas. No sistema encontram-se basicamente dois tipos de notificações, as notificações de rotina (ordinárias) e as de medidas de urgência. Contudo, os países membros estão constantemente atualizando suas normas, assim eles podem complementar, corrigir ou até mesmo substituir a notificação original (ordinária). Os Gráficos apresentados neste trabalho englobam todos os tipos anteriormente citados.

O Gráfico 1 representa o total de notificações apresentadas à OMC. Observa-se que a cada ano aumenta a participação dos países, demonstrando o compromisso deles em relação ao princípio da transparência. Em 1995, foram apresentadas à OMC 197 notificações, ante 1.400 de 2010.

\footnotetext{
${ }^{5}$ Sigla em inglês: Hazard Analysis and Critical Control Point (HACCP).
}

${ }^{6}$ Sigla em inglês: Sanitary and Phytosanitary Measures Agreement (SPS). 


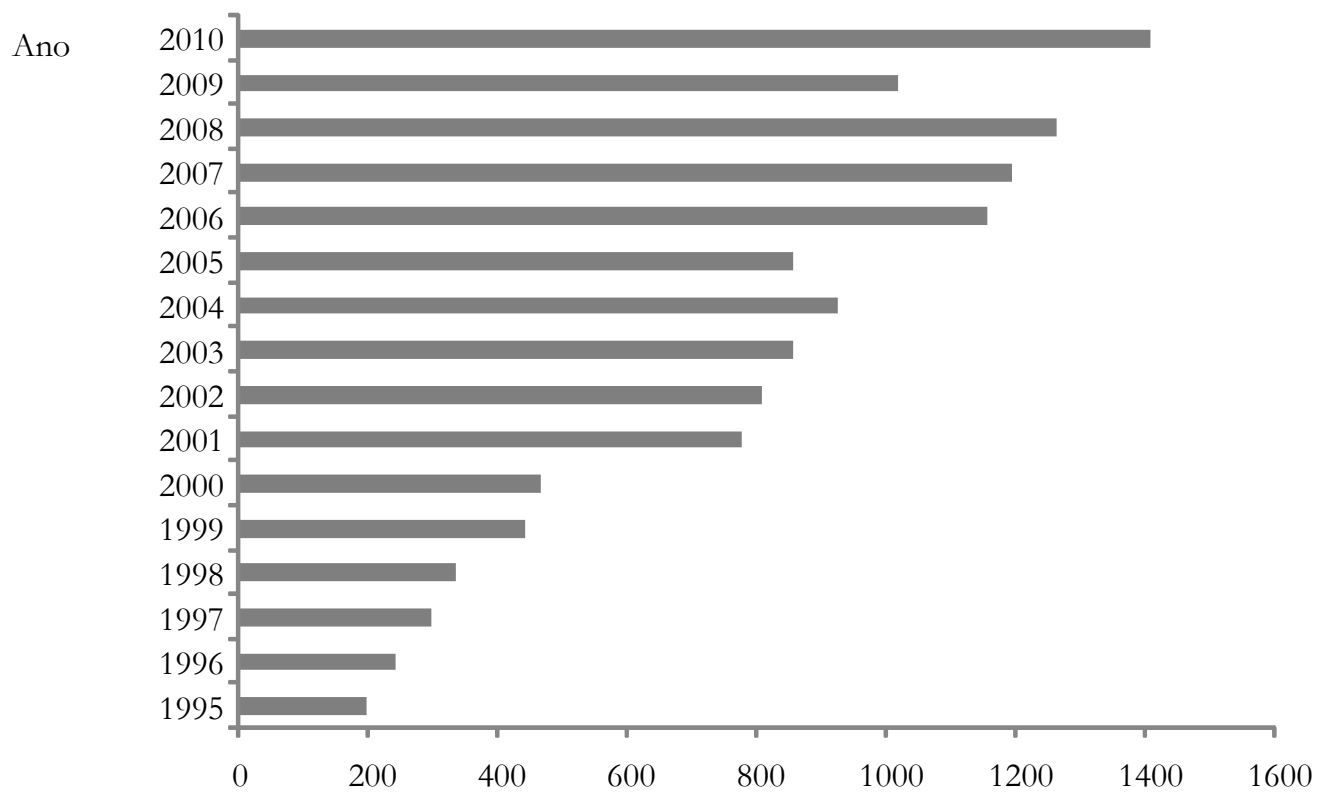

Número de notificações

Gráfico 1. Número total de notificações apresentadas à Organização Mundial de Comércio (OMC) no período de 1995 a 2010, de acordo com o Registro Central de Notificações da OMC (2010).

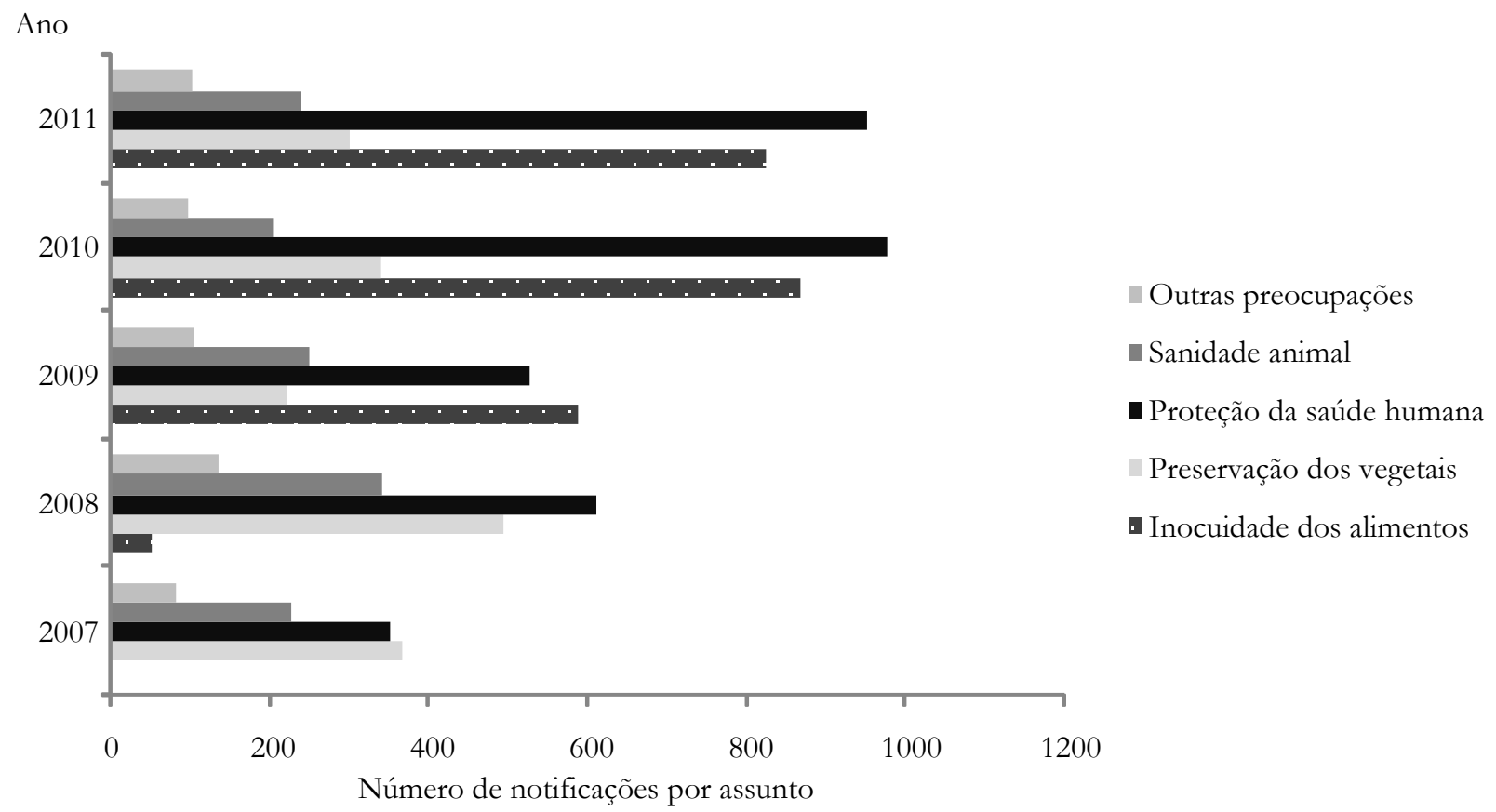

Gráfico 2. Número de notificações por assunto apresentadas à Organização Mundial de Comércio (OMC), no período de 2007 a 2011, de acordo com o Registro Central de Notificações da OMC (2011). 
O Gráfico 2 demonstra os assuntos que suscitaram maior preocupação por parte dos membros da OMC nos anos de 2007 à 2011. Nota-se que aproximadamente $37 \%$ das preocupações comerciais dos países se relacionaram com a proteção da saúde humana, $25 \%$ com a inocuidade do alimento, $19 \%$ com a preservação vegetal, $14 \%$ com a sanidade animal e $5 \%$, outras preocupações. Essas notificações ratificam os objetivos principais do Codex, que é proteger a saúde humana e garantir práticas transparentes no comércio.

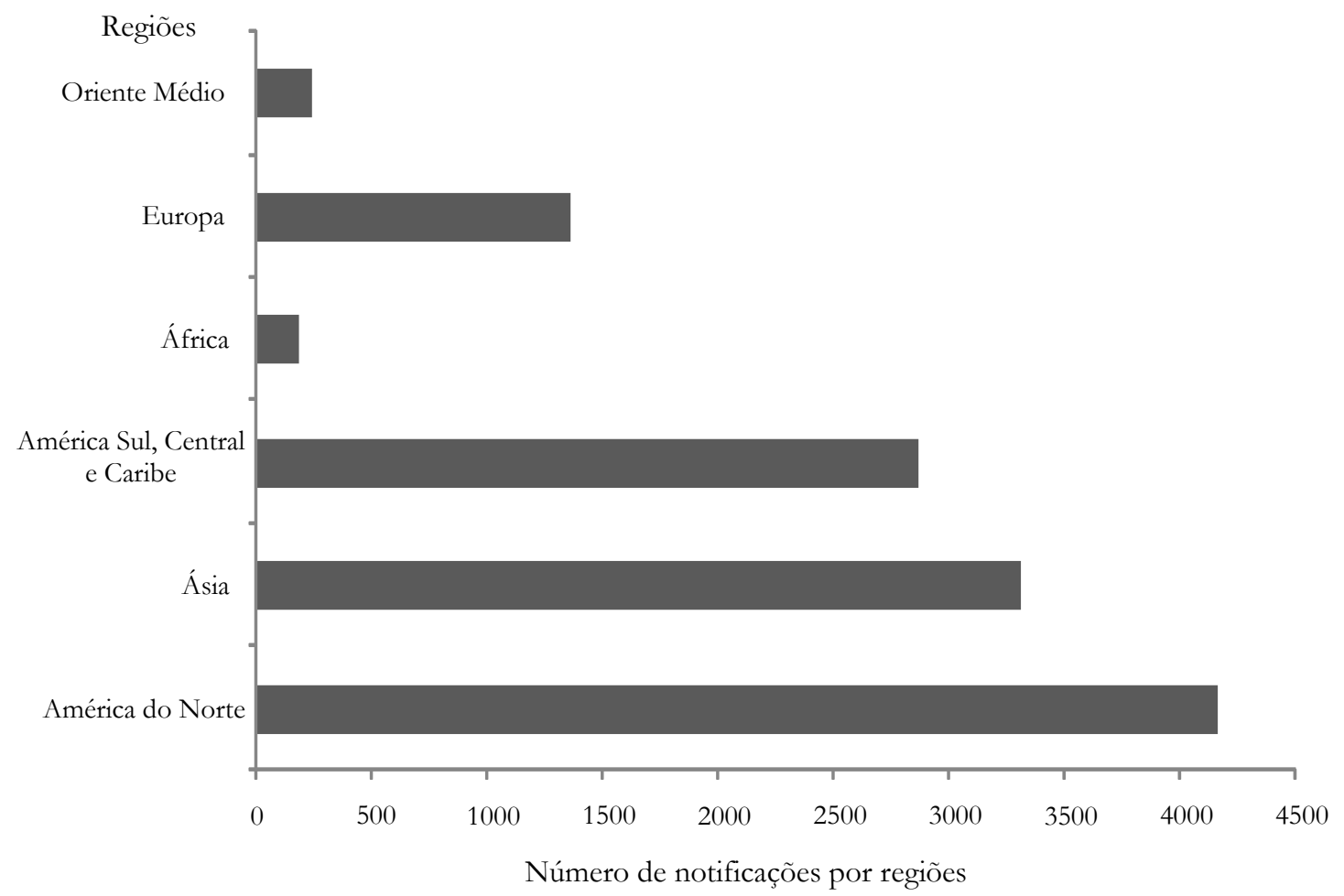

Gráfico 3. Notificações por regiões, período 1995 a 2010, de acordo com o Registro Central de Notificações da Organização Mundial do Comércio (OMC), 2010.

O Gráfico 3 apresenta as notificações por regiões. A região que mais notificou no período de 1995 a 2010 foi a América do $\mathrm{Norte}^{7}$, com 4.020 notificações (aproximadamente 34\%), com destaque para os Estados Unidos, o qual apresentou maior parte das notificações desta região. A segunda região que mais notificou foi a Ásia ${ }^{8}$, a qual enviou 3.174

\footnotetext{
${ }^{7}$ Os países que fazem parte da América do Norte, segundo as definições de grupo da OMC, são: Bermudas, Canadá, México, Poto Rico, São Pedro e Miquelon, Estados Unidos e U. S. Ilhas Virgens.

8 Os países que fazem parte da Ásia, segundo as definições de grupo da OMC, são: Afeganistão, Austrália, Bangladesh, Butão, Brunei, Darussalam, Camboja, China, Coreia do Sul, Coreia do Norte, Fiji, Filipinas, Guam,
}

notificações (aproximadamente 26\%) à OMC, com destaque para a Austrália, Nova Zelândia, República da Coreia, Indonésia, China e Taipé Chinês. A terceira região que mais notificou foi a América do Sul, Central

Hong Kong, Índia, Indonésia, Christmas Island, Norfolk Island, Ilhas Cocos (Keeling), Ilhas Cook, Ilhas Marianas, Ilhas Marshall, Ilhas Menores Distantes dos Estados Unidos, Ilhas Salomão, Japão, Kiribati, Macau, China, Malásia, Maldivas, Micronésia, Estados Federados da Mongólia, Mianmar, Nauru, Nepal, Niue, Nova Caledônia, Nova Zelândia, Paquistão, Palau, Papua Nova Guiné, Pitcairn, Polinésia Francesa, República Democrática Popular do Laos, Samoa, Samoa Americana, Singapura, Sri Lanka, Tailândia, Taipé Chinês, Timor-Leste, Tokelau, Tonga, Tuvalu, Vanuatu, Vietnã, Wallis e Futuna. 
e Caribe ${ }^{9}$, com 2.845 (aproximadamente 24\%). Entre os países desta região, Argentina, Brasil, Chile e Peru foram os países que mais apresentaram notificações. A Europa $^{10}$ se apresenta em quarto lugar, com 1.401 notificações (aproximadamente 12\%), com destaque para União Europeia. A África ${ }^{11}$ e o Oriente Médio ${ }^{12}$ foram as duas regiões que menos notificaram com uma participação ínfima de 2\% cada região.

Apesar da significativa participação dos países membros disponibilizando várias informações sobre a adoção e implantação de medidas sanitárias e fitossanitárias, com o intuito de conter a proliferação das mesmas como forma de restrição ao comércio, ainda vários países enfrentam uma série de dificuldades. Um estudo do Banco Mundial em parceria com a OMC, intitulado "O Impacto das Medidas Sanitárias e Fitossanitárias na Exportação Agrícola e de Produtos Alimentares de Países em Desenvolvimento" 13 , demonstrou a dificuldade que os países em desenvolvimento possuem no atendimento

${ }^{9}$ Os países que fazem parte da América do Sul, Central e Caribe, segundo as definições de grupo da OMC, são: Anguilla, Antígua e Barbuda, Antilhas Holandesas, Argentina, Aruba, Bahamas, Barbados, Belize, Bolívia, Estado Plurinacional, Brasil, Chile, Colômbia, Costa Rica, Cuba, Dominica, Equador, El Salvador, Geórgia do Sul, Granada, Guatemala, Guiana, Haiti, Honduras, Ilhas Caymans, Ilhas Falkland (Malvinas), Ilhas Turks e Caicos, Ilhas Virgens Britânicas, Jamaica, Montserrat, Nicarágua, Panamá, Paraguai, Peru, República Bolivariana da Venezuela, República Dominicana, São Cristóvão e Nevis, São Vicente e Granadinas, Santa Lúcia, Suriname, Trinidad e Tobago, Uruguai.

${ }^{10}$ Os países que fazem parte da Europa, segundo as definições de grupo da OMC, são: Albânia, Alemanha, Andorra, Áustria, Bélgica, Bósnia e Herzegovina, Bulgária, Chipre, Croácia, Dinamarca, Eslovénia, Espanha, Estónia, Antiga República Jugoslava da Macedónia, Finlândia, França, Gibraltar, Grécia, Gronelândia, Hungria, Irlanda, Islândia, Ilhas Feroé, Itália, Letónia, Liechtenstein, Lituânia, Luxemburgo, Malta, Monaco, Montenegro, Noruega, Holanda, Polónia, Portugal, Reino Unido, República Checa, República Eslovaca, Roménia, São Marino, Santa Sé, Sérvia, Suécia, Suiça, Svalbard e Ilha Jan Mayen, Turquia,União Europeia.

${ }_{11}$ Os países que fazem parte da África, segundo as definições de grupo da OMC, são: Angola, Argélia, Benin, Botswana, Burkina Faso, Burundi, Cabo Verde, Camarões, Chade, Comores, Congo, Côte d'Ivoire, Djibouti, Egito, Eritreia, Etiópia, Gabão, Gâmbia, Gana, Guiné, Guiné Equatorial, Guiné-Bissau, Ilha Bouvet, Ilhas Heard e McDonald, Jamahiriya Árabe Líbia, Quénia, Lesoto, Libéria, Madagascar, Malawi, Mali, Marrocos, Maurícias, Mauritânia, Mayotte, Moçambique, Namíbia, Níger Nigéria, Central Africano República, República Democrática do Congo, Ruanda, Sahara Ocidental, Santa Elena, São Tomé e Príncipe, Senegal, Seychelles, Serra Leoa, Somália, África do Sul, Sudão, Suazilândia, Tanzânia, Território Britânico do Oceano Índico, Territórios Franceses do Sul, Togo, Tunísia, Uganda, Zâmbia, Zimbabué.

12 Os países que fazem parte do Oriente Médio, segundo as definições de grupo da OMC, são: Bahrein, Reino da Arábia Saudita, Emirados Árabes Unidos, Irã, República Islâmica do Iraque, Israel, Jordan, Kuwait, Autoridade Palestiniana na Cisjordânia e na Faixa de Gaza, Líbano, Omã, Qatar, República Árabe da Síria, Iémen.

13 Henson et al. The impact of sanitary and phytosanitary measures on developing country exports of agricultural and food products. Paper prepared for World Bank's Integrated Program of Research and Capacity Building to enhance participation of developing countries in the WTO 2000 negotiations. Genebra; 1999. às exigências do Acordo de Medidas Sanitárias e Fitossanitárias da OMC, devido ao problema de acesso aos conhecimentos científicos e técnicos ${ }^{14}$.

\section{CONSIDERAÇÕES FINAIS}

O Codex Alimentarius é um Programa conjunto FAO/OMS de normas alimentares, de caráter internacional, referente à produção, à elaboração e à distribuição de alimentos, formulado com os objetivos de proteger a saúde do consumidor e assegurar práticas equitativas de comércio de produtos alimentícios. A partir de 1995, com a criação da OMC e do Acordo sobre Medidas Sanitárias e Fitossanitárias, o Codex passou a ser ponto de referência no comércio internacional. Isso implica que o Codex foi ligado a um poderoso instrumento jurídico para regulamentar o comércio mundial de alimentos.

É importante salientar que as normas, práticas e diretrizes do Codex atuam sob todos os agentes econômicos da cadeia produtiva agroalimentar, assim, seu campo de influencia vai desde o produtor, passa pelo processador e distribuidor até o fim da cadeia que é o consumidor final. O Codex Alimentarius contém mais de 300 normas para alimentos ou grupos de alimentos. Inclui a Norma Geral para os rótulos dos alimentos pré-embalados, as Diretrizes Gerais sobre a Declaração de Propriedade e as Diretrizes sobre a qualidade nutricional dos alimentos, que têm por objetivo assegurar a qualidade dos alimentos. Portanto, essas medidas "forçam" os países membros a adequarem sua produção às normas estabelecidas internacionalmente.

A atuação do Codex no mercado internacional, por meio da tendência de harmonização das normas e regras referentes à produção e elaboração dos alimentos, sinaliza dois caminhos, no mínimo paradoxal: de um lado, uma maior dinâmica para o comércio; de outro, a criação de barreiras ao próprio comércio, pois as normas Codex poderiam se apresentar como um empecilho para os países em desenvolvimento, devido aos elevados custos relacionados ao processo de elaboração de normas.

\footnotetext{
14 The problems developing countries have in complying with SPS requirements reflect their wider resource and infrastructure constraints that limit not only their ability to comply with SPS requirements, but also their ability to demonstrate compliance. A particularly acute problem is access to appropriate scientific and technical expertise. Indeed, in many developing countries knowledge of SPS issues is poor, both within government and the food supply chain, and the skills required to assess SPS measures applied by developed countries are lacking (Henson et al., 1999) ${ }^{[14]}$.
} 
Assim, acredita-se que, ao fazer parte dos Acordos da OMC, o Codex passou a integrar a agenda política internacional, fazendo parte de um poderoso arcabouço legal para regulamentação do mercado de alimentos. Os países desenvolvidos são os maiores beneficiários desses acordos, uma vez que possuem maior grau de organização, tanto no campo científicotecnológico, quanto no jurídico, para seguir essas normas e cobrar suas aplicações. Entretanto, os países em desenvolvimento precisam definir políticas públicas e de aperfeiçoamento de seus sistemas de controle, prevenção e inspeção, cuja capacidade e custos vêm apresentando dificuldades.

\section{AGRADECIMENTOS}

Os autores agradecem à FAPEMIG (Fundação de Amparo à Pesquisa do Estado de Minas Gerais) pelo apoio financeiro para a realização desse trabalho.

\section{REFERÊNCIAS}

[1] Pessanha L. Segurança alimentar como princípio orientador de políticas públicas: implicações e conexões ao caso brasileiro [tese]. Rio de Janeiro: Instituto de Ciências Humanas e Sociais, Universidade Rural do Rio de Janeiro; 1998. $317 \mathrm{p}$.

[2] Organización de las Naciones Unidas para la Agricultura y la Alimentación (FAO). WFS/TECH/7. Evaluación de la seguridad alimentaria. Versión provisional; 1996.

[3] Menezes F. Segurança Alimentar: um conceito em disputa e construção. IBASE, Rio de Janeiro: IBASE; 2001.

[4] Cumbre Mundial sobre la Alimentación. Declaración de Roma sobre la Seguridad Alimentaria Mundial. Roma, 1996 [consultado el 21 de agosto 2006]. Disponible: http://www.fao.org/docrep/003/w3613s/w3613s00.htm

[5] Nojosa GBA, Alencar MAA, Da Silva RP. Transparência de medidas SPS no agronegócio brasileiro. In: Notificações aos acordos Barreias Técnicas (TBT) e Sanitárias da OMC: transparência comercial ou barreiras não tarifárias? Departamento de Economia/Editor Orlando Monteiro da Silva. Universidade Federal de Viçosa: FAPEMIG; 2010.

[6] Presser MF, Almeida LT. Negociaciones internacionales y seguridad alimentaria: perspectivas para el MERCOSUR.
In: Políticas de seguridad alimentaria y nutrición en América Latina/Organizador Walter Belik. São Paulo: Hucitec; 2004. p. 223-82.

[7] Azevedo AC. “Alerta Exportador!": a questão informacional no tratamento das barreiras técnicas [acesso em 15 ago 2010]. Disponível em: http://www.inmetro.gov.br

[8] Almeida JS. Acordo sobre a aplicação de medidas sanitárias e fitossanitárias: balanço de uma década buscando o equilíbrio entre a proteção do comércio e a proteção da saúde dos consumidores. Divisão de Comércio Internacional e Integração. Santiago de Chile: CEPAL; 2005.

[9] Thorstensen V. Organização Mundial do comércio (OMC): as regras do comércio internacional e a nova rodada de negociações multilaterais. 2 o ed. São Paulo: Ed. Aduaneiras; 2001.

[10] Veggeland F, Borgen SO. Negotiating International Food Standards: The World Trade Organization's Impact on the Codex Alimentarius Commission. An International Journal of Policy, Administration, and Institutions. 2005;18(4):675-708.

[11] Comisión del Codex Alimentarius. Manual de procedimento. 20 o edición. Organización Mundial de La Salud y Organización de lãs Naciones Unidas para la Agricultura y laAlimentación. Roma; 2011. p. 231.

[12] Que és Codex Alimentarius. Secretaría del Programa Conjunto FAO/OMS sobre Normas Alimentarias Organización de las Naciones Unidas para la Agricultura y la Alimentación. Roma; 2006. p. 51.

[13] Martinelli MA. O Codex Alimentarius e a Inocuidade dos alimentos. UNICAMP: FODEPAL. In: Políticas de seguridad alimentaria y nutrición en América Latina/Organizador Walter Belik. São Paulo: Hucitec; 2004. p. 203-22.

[14] Henson S, Loader R, Swinbank A, Bredahl M. The impact of sanitary and phytosanitary measures on developing country exports of agricultural and food products. Paper prepared for World Bank's Integrated Program of Research and Capacity Building to enhance participation of developing countries in the WTO 2000 negotiations. Genebra; 1999. 